\title{
HIGH SENSITIVE C-REACTIVE PROTEIN AND ITS RELATIONSHIP WITH OTHER CARDIOVASCULAR RISK VARIABLES IN OBESE, OVERWEIGHT AND HEALTHY INDIVIDUALS
}

\author{
GAYATHRI B*, VINODHINI VM
}

Department of Biochemistry, SRM Medical College Hospital and Research Centre, Kattankulathur, SRM University, Kanchipuram - 603 203, Tamil Nadu, India. Email: drgayathri2016@gmail.com

Received: 19 March 2018, Revised and Accepted: 25 April 2018

\begin{abstract}
Objective: More than $50 \%$ of the world's population is considered overweight and being overweight is associated with several comorbidities such as Type 2 diabetes mellitus, hypertension, cardiovascular diseases, dyslipidemia, respiratory diseases, osteoarthritis, and depression. Therefore, in this study, we have estimated the high sensitive C-reactive protein (hs-CRP) levels in obese, overweight, and normal body mass index (BMI) individuals and whether there was any relationship between hs-CRP and other risk factors of the cardiovascular system such as serum total cholesterol (TC) and other lipids.
\end{abstract}

Methods: A total of 150 participants, divided into three groups. Group I - 50 participants with normal BMI (18-22.99 kg/m²), Group II - 50 participants who were overweight (BMI $=23-24.99 \mathrm{~kg} / \mathrm{m}^{2}$ ), and Group III - 50 who were obese (BMI $\left.\geq 25 \mathrm{~kg}\right)$. We measured fasting plasma glucose, postprandial plasma glucose, serum TC, triacylglycerol, low-density lipoprotein cholesterol, high-density lipoprotein cholesterol, and hs-CRP.

Results: Obese individuals had increased hs-CRP compared with control (Group I) and overweight (Group II) groups. hs-CRP positively correlated with BMI and lipid profile.

Conclusion: Elevated hs-CRP was associated with cardiovascular risk factors in overweight and obese individuals. This high-risk group should be targeted for therapeutic lifestyle modifications to prevent further complications.

Keywords: Cardiovascular disease, High sensitive C-reactive protein, Obesity.

(C) 2018 The Authors. Published by Innovare Academic Sciences Pvt Ltd. This is an open access article under the CC BY license (http://creativecommons. org/licenses/by/4. 0/) DOI: http://dx.doi.org/10.22159/ajpcr.2018.v11i8.26056

\section{INTRODUCTION}

The rapidly growing rate of obesity is a severe health problem [1]. The basic cause of this problem is mostly due to the imbalance between energy intake and expenditure which induces an excessive accumulation of body fat [2]. Obesity is a chronic disorder prevalent in both developed and developing countries. More than half of the world's population is considered overweight and being overweight is associated with several comorbidities such as Type 2 diabetes mellitus, cardiovascular diseases (CVD), hypertension, dyslipidemia, respiratory disease, osteoarthritis, and depression [3]. It has been shown that pro-inflammatory molecules contribute to the development of complications in obesity [4]. These conditions are operationally defined by a surrogate measurement that correlates with body fat, body mass index (BMI), defined as body weight (kg) divided by the square of height $\left(\mathrm{m}^{2}\right)$.

BMI is the most commonly used method for describing obesity and assessing the risk for obesity-related diseases [5]. CVD is now recognized to be a process involving inflammatory processes, and serum inflammatory markers are considered to be important for the evaluation of cardiovascular risk [6]. It is possible that the relationship between CVD risk and obesity is linked to the increased inflammatory milieu [7]. High sensitive C-reactive protein (hs-CRP), an inflammatory marker, has been considered as an important indicator of cardiovascular risk [8]. Obesity has been associated with a chronic, low-level activation of the acute-phase response $[9,10]$, suggesting that it is an "inflammatory disease." It is still not clear whether inflammatory parameters are markers or mediators of insulin resistance and CVD. The increased production of cytokines and acute-phase response proteins, such as hs-CRP, which occurs in obesity, is related to insulin resistance, endothelial dysfunction, and atherosclerosis [11]. CRP is a member of the pentraxin family of proteins. It is an acute phase reactant synthesized mainly by the liver in response to stimulation by pro-inflammatory cytokines and adipocytes [12]. Serum CRP levels are elevated in response to acute infections, inflammatory conditions, and trauma. In these clinical situations, the serum CRP levels rise rapidly generally beyond $10 \mathrm{mg} / \mathrm{dl}$ with a concomitant elevation of erythrocyte sedimentation rates [13].

We planned the present study to investigate a state of chronic lowgrade systemic inflammation by measuring serum hs-CRP levels in overweight and obese individuals and comparing them with a group of age and sex matched controls with normal BMI.

\section{METHODS}

This cross-sectional study included a total of 150 (group 1=50 normal BMI, group 2=50 overweight, and group 3=50 obese) individuals, aged between 18 and 54 years, who have attended the Master health Checkup Programme of SRM Medical College Hospital and Research Centre between June 2016 and March 2017 and met the research criteria. The study was approved by the Institutional Ethical Committee of SRM Medical College Hospital and Research Centre, and written informed consent was obtained from all the participants (IEC no -957) IEC/2016).

The important confounding variables such as diabetes mellitus, hypertension, smoking, alcohol intake, acute or chronic infections, and history of drug intake were excluded. According to consensus statement, normal BMI is $18.0-22.9 \mathrm{~kg} / \mathrm{m}^{2}$, overweight is $23.0-24.9 \mathrm{~kg} / \mathrm{m}^{2}$, and obesity is $\geq 25 \mathrm{~kg} / \mathrm{m}^{2}[14]$. 
We have included three groups based on the BMI Group 1 (Normal) BMI $=18.0-22.9 \mathrm{~kg} / \mathrm{m}^{2}$, Group 2 (Overweight) $\mathrm{BMI}=23.0-24.9 \mathrm{~kg} / \mathrm{m}^{2}$, and Group 3 (Obese) BMI $\geq 25 \mathrm{~kg} / \mathrm{m}^{2}$ [15].

\section{Anthropometric measurements}

BMI, calculated as weight $(\mathrm{kg})$ divided by height $\left(\mathrm{m}^{2}\right)$, was used as a measure of overall obesity. Anthropometric measurements such as body weight and height were measured by the same observer in the morning. Body height and weight were measured using a stadiometer and a standardized scale, respectively.

\section{Biochemical parameters}

Two $\mathrm{ml}$ blood was collected in a fluoride oxalate vacutainer for glucose measurement and measured immediately using automated chemistry analyzer (BECKMAN COULTER AU 480). Five ml blood was collected in a plain vacutainer. Serum was separated after centrifugation at 3,000 RPM for $10 \mathrm{~min}$ and lipid profile parameters, namely total cholesterol (TC) (cholesterol oxidase method), triglycerides (glycerol phosphate oxidase peroxidase), low-density lipoprotein cholesterol (LDL-C direct method), and high-density lipoprotein cholesterol (HDL-C direct method) were measured immediately using automated chemistry analyzer (BECKMAN COULTER AU 480). Postprandial sample collected for plasma glucose (PPG) measurement. Cholesterol/HDL-C and LDL-C/ HDL-C ratios were calculated by subdividing TC and LDL-C, respectively, by HDL-C. $0.5 \mathrm{ml}$ of serum sample stored in a deep freezer at $-20^{\circ}$ for 2 months for estimation of serum hs-CRP. Estimation of serum hs-CRP was carried out by turbidimetry latex-high sensitivity kit in OLYMPUS AU400.

\section{Statistical analysis}

Statistical comparisons were carried out by Student's t-test and oneway ANOVA tests. Correlations were done by calculating Pearson's correlation coefficient. This was conducted using IBM SPSS Statistics 20. Simple descriptive statistics (mean and Standard Deviation) were used to describe the observed variation in lipid profile, hs-CRP, fasting plasma glucose (FPG), and PPG between the groups under the study.

\section{RESULTS AND DISCUSSION}

The total number of subjects included in this analysis was 150, of which 50 had BMI $\geq 25 \mathrm{~kg} / \mathrm{m}^{2}$ (obese), 50 had BMI in the range of $23-24.9 \mathrm{~kg} / \mathrm{m}^{2}$ (overweight), and 50 participants were age and sex matched with normal BMI (18-22.9 $\left.\mathrm{kg} / \mathrm{m}^{2}\right)$ which formed the control group.

Table 1 shows the measured parameters of the three study groups.

The differences in serum hs-CRP levels between the three groups tested using one-way ANOVA method were found to be statistically significant ( $[F=88.070], p \leq 0.00001)$. The difference between the levels of BMI, FPG, PPG, TC, triacylglycerol (TGL), LDL-C, and very LDL-C tested by one-way ANOVA method was also found to be statistically significant across the three groups (Tables 2 and 3 ).
There was a positive correlation between hs-CRP levels and BMI in obese and overweight individuals (Figs. 1-3).

In this study, we showed that hs-CRP levels were higher in obese and overweight individuals when compared with age- and sex-matched normal BMI individuals. hs-CRP was positively correlated with BMI, TC, LDL-C, and TGL and was negatively correlated with HDL-C. It is considered that clustering of metabolic abnormalities presents synergistic effects on cardiovascular complications beyond the sum of effects of individual abnormalities [16].

Serum levels of hs-CRP have been shown to correlate with future risk of cardiovascular events since an inflammatory component has been well recognized in the atherosclerotic process [17]. Vino et al. reported that the correlation of BMI or waist circumference with hsCRP concentration has also been observed $[18,19]$. In women with polycystic ovary syndrome (PCOS), the levels of hs-CRP, apolipoprotein $\mathrm{B}$, and waist-to-hip ratio were significantly elevated when compared with controls. Screening with hs-CRP and apolipoprotein B may provide a better risk assessment in patients with PCOS [20].

Perceived obesity comorbidity of respondents revealed in this study that majority knew obesity can lead to heart problems, hypertension, and diabetes. The findings of this study can provide baseline data for monitoring the effectiveness of national programs for the prevention and control of obesity in Malaysia [21]. Dutta et al. found that overweight patients significantly took dominance in a low-risk category and there was no significant correlation between AIP, TC, HDL, LDL, TG, and BMI [22].

hs-CRP was positively associated with BMI, WHR, LDL, TC, TG, and PCOS status and was negatively associated with HDL-C [23]. In our study, we found that the difference between the levels of TC, TGL, LDL-C, and VLDL-C was also found to be statistically significant among the three groups.

Subjects who had elevated levels of both leptin and hs-CRP belonged to the highest risk of developing metabolic syndrome [24]. Cutoff

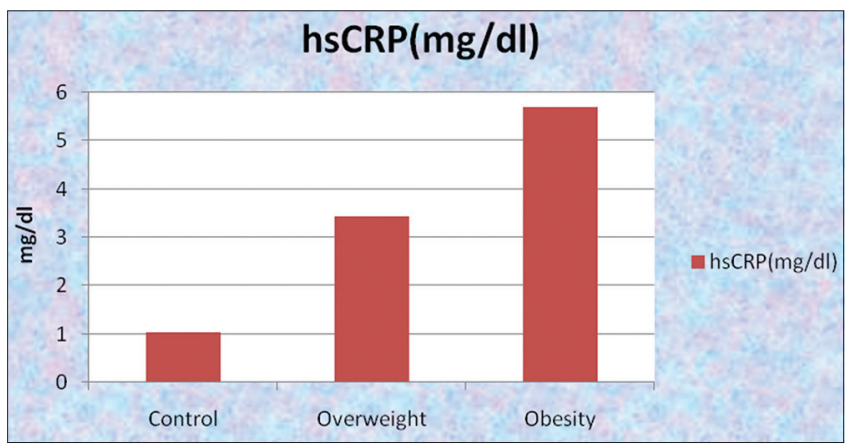

Fig. 1: Mean values of high sensitive C-reactive protein $(\mathrm{mg} / \mathrm{dl})$ of the study groups obese, overweight, and healthy

Table 1: Mean \pm standard deviation of measured parameters of the study groups

\begin{tabular}{|c|c|c|c|}
\hline \multirow[t]{2}{*}{ Parameter } & \multirow{2}{*}{$\begin{array}{l}\text { Group I } \\
\text { Control }(n=50) \text { Mean } \pm S D\end{array}$} & \multirow{2}{*}{$\begin{array}{l}\text { Group II } \\
\text { Overweight }(n=50) \text { Mean } \pm S D\end{array}$} & \multirow{2}{*}{$\begin{array}{l}\text { Group III } \\
\text { Obese }(n=50) \text { Mean } \pm S D\end{array}$} \\
\hline & & & \\
\hline BMI $\left(\mathrm{kg} / \mathrm{m}^{2}\right)$ & $20.16 \pm 1.5$ & $23.67 \pm 0.57$ & $30.02 \pm 4.27$ \\
\hline hsCRP (mg/dl) & $1.04 \pm 0.63$ & $3.43 \pm 0.84$ & $5.69 \pm 2.85$ \\
\hline $\mathrm{FPG}(\mathrm{mg} / \mathrm{dl})$ & $95 \pm 11$ & $94 \pm 14$ & $104 \pm 13$ \\
\hline PPPG (mg/dl) & $111 \pm 15$ & $111 \pm 16$ & $123 \pm 14$ \\
\hline $\mathrm{TC}(\mathrm{mg} / \mathrm{dl})$ & $155 \pm 18$ & $161 \pm 23$ & $192 \pm 35$ \\
\hline TGL (mg/dl) & $113 \pm 28$ & $145 \pm 51$ & $205 \pm 65$ \\
\hline HDL-C (mg/dl) & $41 \pm 9$ & $41 \pm 5$ & $38 \pm 6$ \\
\hline LDL-C (mg/dl) & $91 \pm 18$ & $91 \pm 26$ & $113 \pm 34$ \\
\hline VLDL-C (mg/dl) & $23 \pm 6$ & $29 \pm 10$ & $41 \pm 13$ \\
\hline TC/HDL-C & $3.98 \pm 1.02$ & $40.0 \pm 7.0$ & $5.18 \pm 1.17$ \\
\hline LDL-C/HDL-C & $2.39 \pm 0.88$ & $2.27 \pm 0.7$ & $3.06 \pm 1.04$ \\
\hline
\end{tabular}

BMI: Body mass index, hs-CRP: High sensitive C-reactive protein, TC: Total cholesterol, TGL: Triacylglycerol, FPG: Fasting plasma glucose, PPPG: Postprandial plasma glucose, LDL-C: Low-density lipoprotein cholesterol, HDL-C: High-density lipoprotein cholesterol, VLDL-C: Very low-density lipoprotein cholesterol 
Table 2: Comparison of biochemical parameters between the three groups using one-way ANOVA

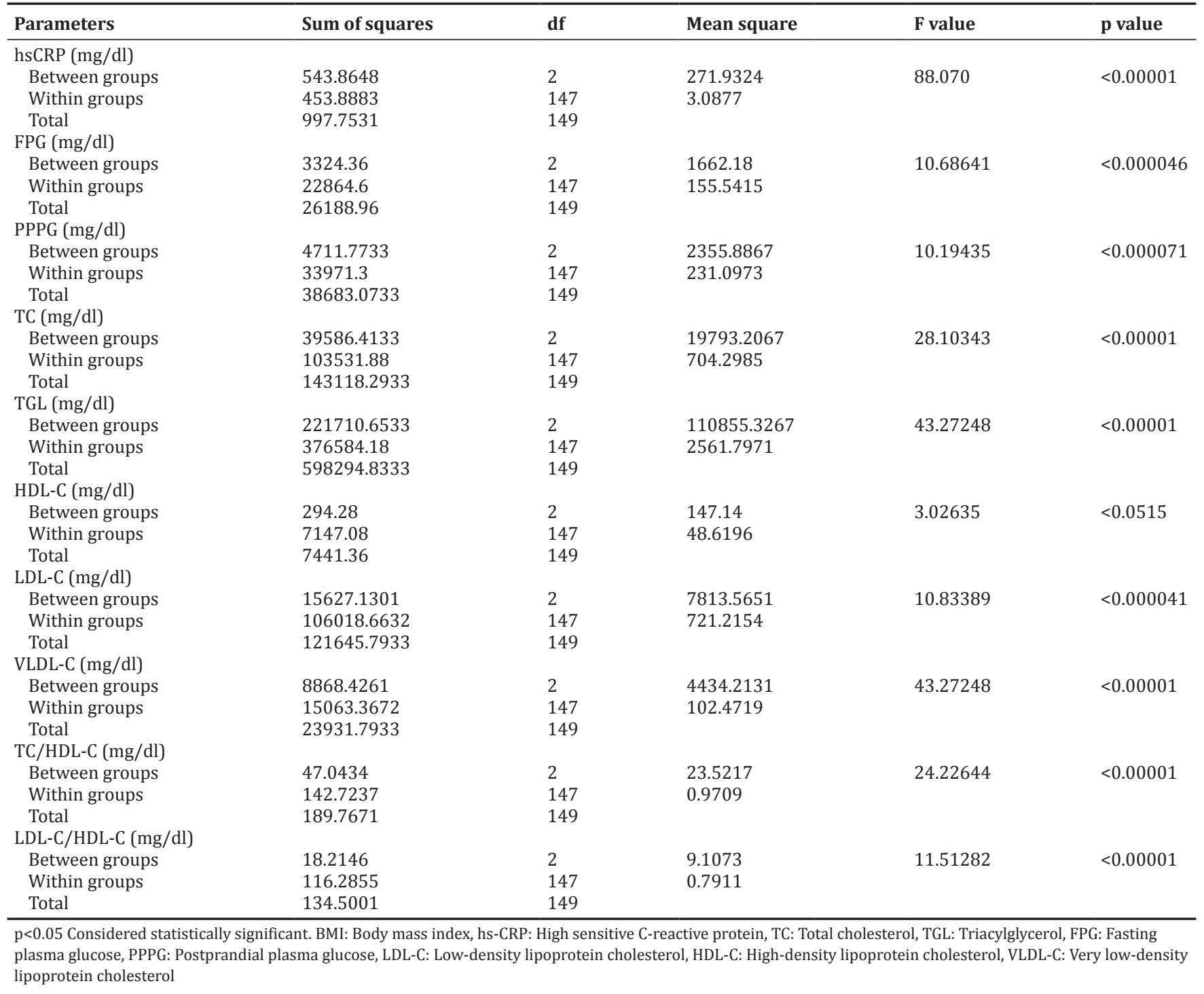

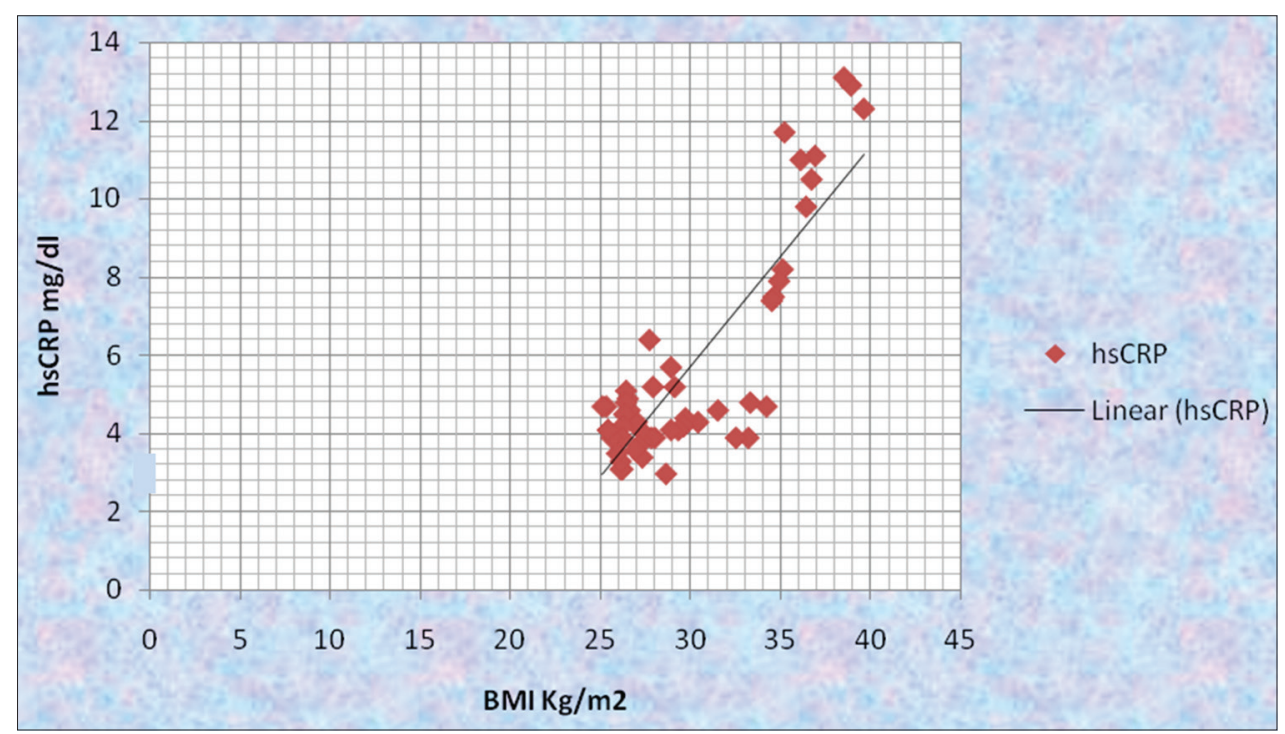

Fig. 2: Correlation of body mass index and high sensitive C-reactive protein $(\mathrm{mg} / \mathrm{dl})$ in obesity group 
Table 3: Correlation between hs-CRP and lipid parameters among the three groups

\begin{tabular}{llll}
\hline Parameters & $\begin{array}{l}\text { Controls } \\
\text { (r value) }\end{array}$ & $\begin{array}{l}\text { Overweight } \\
\text { (r value) }\end{array}$ & $\begin{array}{l}\text { Obese } \\
\text { (r value) }\end{array}$ \\
\hline $\begin{array}{l}\text { BMI } \\
\text { hsCRP }\end{array}$ & 0.291 & 0.525 & 0.855 \\
TC & 0.168 & 0.035 & 0.209 \\
$\begin{array}{l}\text { hsCRP } \\
\text { TGL } \\
\text { hsCRP }\end{array}$ & 0.396 & 0.151 & 0.748 \\
$\begin{array}{l}\text { HDL } \\
\text { hsCRP }\end{array}$ & -0.163 & 0.068 & 0.097 \\
$\begin{array}{l}\text { LDL } \\
\text { hsCRP }\end{array}$ & 0.129 & 0.180 & 0.192 \\
\hline
\end{tabular}

BMI: Body mass index, hs-CRP: High sensitive C-reactive protein, TC: Total cholesterol, TGL: Triacylglycerol, LDL: Low-density lipoprotein, HDL: High-density lipoprotein

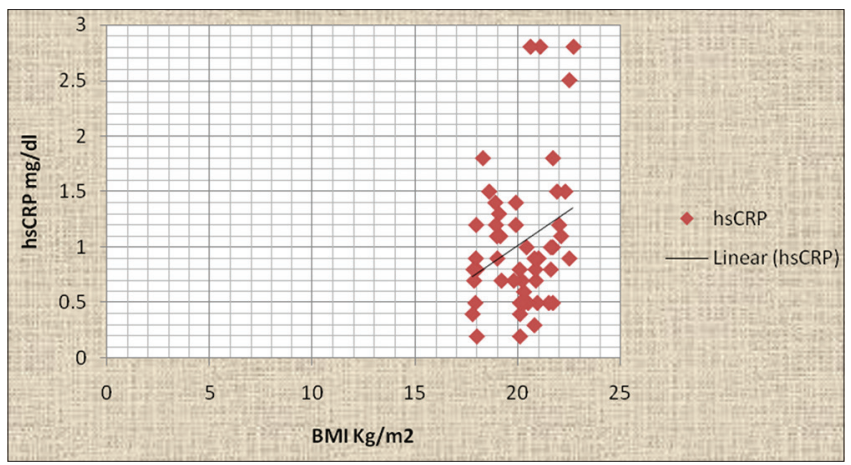

Fig. 3: Correlation between body mass index (BMI) and high sensitive C-reactive protein $(\mathrm{mg} / \mathrm{dl})$ in normal BMI group

limits $>3 \mathrm{mg} / \mathrm{dl}$ in Hs-CRP levels indicate low-grade inflammation, which, in turn, might be a prognostic marker for further cardiovascular events [25]. The expansion of the adipose tissue leads to the altered production of pro-inflammatory molecules and results in low-grade inflammation. The increase in hs-CRP levels indicates a state of lowgrade inflammation in the obese group [26].

Hak et al. [27] found that CRP was strongly related to BMI and the waist and hip circumferences separately; however, after adjustment for BMI, waist circumference was still related to CRP, whereas hip circumference was not.

There was a close relationship between hs-CRP and cardiovascular risk factors such as BMI, LDL-C, TC, HDL-C, and TGL. Limitations of this study are smaller sample size, and a prospective study is required to stratify the risk category among obese.

\section{CONCLUSION}

Our result suggests a strong correlation between indices of adiposity and elevated hs-CRP levels. Serum hs-CRP is an inexpensive, simple tool to predict cardiac risk in apparently healthy individuals at an early stage. Elevated hs-CRP was associated with cardiovascular risk factors in both overweight and obese individuals. This high-risk group should be targeted for therapeutic lifestyle modifications to prevent further complications. Screening of these apparently healthy individuals with the adjuvant novel biomarker hs-CRP will help in global cardiovascular risk assessment.

\section{ACKNOWLEDGMENTS}

The authors would like to thank the staff of SRM Medical College Hospital and Research Centre, Kattankulathur and the participants for their great support.

\section{AUTHOR'S CONTRIBUTION}

None.

\section{CONFLICTS OF INTEREST}

The authors declare that they have no conflicts of interest.

\section{REFERENCES}

1. York DA, Rössner S, Caterson I, Chen CM, James WP, Kumanyika S, et al. Prevention conference VII: Obesity, a worldwide epidemic related to heart disease and stroke: Group I: Worldwide demographics of obesity. Circulation 2004;110:e463-70.

2. Spiegelman BM, Flier JS. Obesity and the regulation of energy balance. Cell 2001;104:531-43.

3. Golay A, Ybarra J. Link between obesity and Type 2 diabetes. Best Pract Res Clin Endocrinol Metab 2005;19:649-63.

4. Trayhurn P, Wood IS. Adipokines: Inflammation and the pleiotropic role of white adipose tissue. Br J Nutr 2004;92:347-55.

5. Rothman KJ. BMI-related errors in the measurement of obesity. Int J Obes (Lond) 2008;32 Suppl 3:S56-9.

6. Rizzo M, Rini G, Berneis K. Inflammation and atherosclerosis: Recent insights and future perspectives. Antiinflamm Antiallergy Agents Med Chem 2008;7:150-1.

7. Wellen KE, Hotamisligil GS. Inflammation, stress, and diabetes. J Clin Invest 2005;115:1111-9.

8. Jialal I, Devaraj S. Role of C-reactive protein in the assessment of cardiovascular risk. Am J Cardiol 2003;91:200-2.

9. Faintuch J, Marques PC, Bortolotto LA, Faintuch JJ, Cecconello I. Systemic inflammation and cardiovascular risk factors: Are morbidly obese subjects different? Obes Surg 2008;18:854-62.

10. Cottam DR, Mattar SG, Barinas-Mitchell E, Eid G, Kuller L, Kelley DE, et al. The chronic inflammatory hypothesis for the morbidity associated with morbid obesity: Implications and effects of weight loss. Obes Surg 2004;14:589-600.

11. Apovian CM, Bigornia S, Mott M, Meyers MR, Ulloor J, Gagua M, et al. Adipose macrophage infiltration is associated with insulin resistance and vascular endothelial dysfunction in obese subjects. Arterioscler Thromb Vasc Biol 2008;28:1654-9.

12. Sartipy P, Loskutoff DJ. Monocyte chemoattractant protein 1 in obesity and insulin resistance. Proc Natl Acad Sci U S A 2003:100:7265-70.

13. Black S, Kushner I, Samols D. C-Reactive Protein. Journal Biological Chemistry. Roberts WL: CDC/AHA. CDC/AHA Workshop on Markers; 2004. p. 48487-90

14. Misra A, Chowbey P, Makkar BM, Vikram NK, Wasir JS, Chadha D, et al. Consensus statement for diagnosis of obesity, abdominal obesity and the metabolic syndrome for Asian Indians and recommendations for physical activity, medical and surgical management. J Assoc Physicians India 2009:57:163-70

15. WHO Expert Consultation. Appropriate body-mass index for Asian populations and its implications for policy and intervention strategies. Lancet 2004:363:157-63

16. Muredach PR, Daniel JR. The metabolic syndrome: More than the sum of its parts? Circulation 2003;108:1546-155.

17. Ridker PM. C-reactive protein. A simple test to help predict a risk of heart attack and stroke. Circulation 2003;108:e81-5.

18. Lear SA, Chen MM, Birmingham CL, Frohlich JJ. The relationship between simple anthropometric indices and C-reactive protein: Ethnic and gender differences. Metabolism 2003;52:1542-6.

19. Lim S, Jang HC, Lee HK, Kimm KC, Park C, Cho NH. The relationship between body fat and C-reactive protein in a middle-aged Korean population. Atherosclerosis 2006;184:171-7.

20. Vinodhini VM, Devisri V, William WE, Akshmi MM, Chandrasekar A, Gnanasambandam $\mathrm{S}$, et al. High sensitive c-reactive protein and apolipoprotein $\mathrm{b}$ levels in polycystic ovary syndrome. Int J Pharm BioSci 2012;3:2

21. San OO, Rao US, Zin T. Prevalence and factors associated with obesity among an adult at the Kampong Kolam, east coast Malaysian peninsula-a cross-sectional study. Int J Pharm Pharm Sci 2017;9 Suppl 3:975-1491.

22. Butt M, Adliah MH, Bakry MM. Lipid profile patterns and the association between glycated haemoglobin ( $\mathrm{HbAlc}$ ) and atherogenic index of plasma (AIP) in diabetes patients at a tertiary care hospital in Malaysia. Int J Pharm Pharm Sci 2017:9 Suppl 6:42-5.

23. Verit FF. High sensitive serum C-reactive protein and its relationship with other cardiovascular risk factors in normal insulinemic polycystic ovary patients without metabolic syndrome. Arch Gynecol Obstet 
2010;281:1009-14

24. Ukkola O, Kesäniemi YA. Leptin and high-sensitivity C-reactive protein and their interaction in the metabolic syndrome in middle-aged subjects. Metab Clin Exp 2007;56:1221-7.

25. Ridker PM. Clinical application of C-reactive protein for cardiovascular disease detection and prevention. Circulation 2003;107:363-9.

26. Chambers JC, Eda S, Bassett P, Karim Y, Thompson SG, Gallimore JR, et al. C-reactive protein, insulin resistance, central obesity, and coronary heart disease risk in Indian Asians from the United Kingdom compared with European whites. Circulation 2001;104:145-50.

27. Hak AE, Stehouwer CD, Bots ML, Polderman KH, Schalkwijk CG, Westendorp IC, et al. Associations of C-reactive protein with measures of obesity, insulin resistance, and subclinical atherosclerosis in healthy, middle-aged women. Arterioscler Thromb Vasc Biol 1999;19:1986-91. 